\title{
Distance Education System for Fostering Exercise Habits in Children with Intellectual Disabilities
}

\author{
Chisato Ohashi ${ }^{\mathrm{a},}$, Shunsuke Akiguchi ${ }^{\mathrm{b}}$ \\ ${ }^{a}$ Department of General Education, National Institute of Technology, Toyama College \\ 1-2 Ebieneriya, Imizu, Toyama, 933-0293, Japan \\ ${ }^{\mathrm{b}}$ Department of Electronics and Computer Engineering, National Institute of Technology, Toyama College \\ 1-2 Ebieneriya, Imizu, Toyama, 933-0293, Japan \\ *Chisato Ohashi: c-ohashi@nc-toyama.ac.jp
}

\begin{abstract}
The obesity rate of children with intellectual disabilities is reportedly much higher than that of children without disabilities. One of the possible reasons is that children with intellectual disabilities are less physically active than children without disabilities. To avoid accidents, children with intellectual disabilities often lead inactive lives indoors. Moreover, studies examining the barriers and facilitators of physical activities and exercise among the parents of children with intellectual disabilities have clearly shown that there is a need for physical activities that these children and their family can do together.

First, we found that the time per day during summer vacation devoted to physical activities was significantly shorter than the time during school days devoted to such activities for children with intellectual disabilities. Children who remain inactive during holidays gain weight easily. Moreover, the state of inactivity can lead to future health problems.

In light of this, we developed a distance health education system for fostering exercise habits in children with intellectual disabilities. The system was built using a smartphone application and a network server for collaborative support involving teachers and family. The smartphone application measures the walking distance using a global positioning system (GPS) and counts the number of steps taken using an accelerometer. The web software presents the state of the child's physical activity using graphs and maps.

We have also conducted a long-term clinical trial using the system with a 10-year-old boy with Down syndrome. The boy wore the smartphone to calculate his amount of physical
\end{abstract}

activity, and we sent daily feedback via email to him and his family to enhance communication with them using the system. No significant difference was found between his amount of physical activity in 2016 and 2017; however, his number of steps increased gradually.

Keywords: Children, Intellectual Disabilities, Exercise Habits, Smartphone Application

\section{Introduction}

Since the 1980s, the fitness and athletic ability of children in Japan have been declining. A contributing factor is that the amount of daily physical activity of children has decreased gradually ${ }^{(1)}$. The change in child play styles from physical play outside, as with sports, to inactive playing inside, such as TV or internet games, has led to the neglect of sports and exercise (2). Consequently, the increasing incidence of children with health problems due to inactivity poses a severe social problem ${ }^{(3)}$. The necessity of exercise opportunities for children has been brought to light recently. In 2010, the Japan Sports Association established guidelines for child physical activity, the "Active Child Program," in collaboration with the Ministry of Education, Culture, Sports, Science and Technology ${ }^{(4)}$.

Some studies have indicated that children with intellectual disabilities have lower levels of physical fitness and higher rates of obesity than children without disabilities. The main reasons are inferred to be their movement 


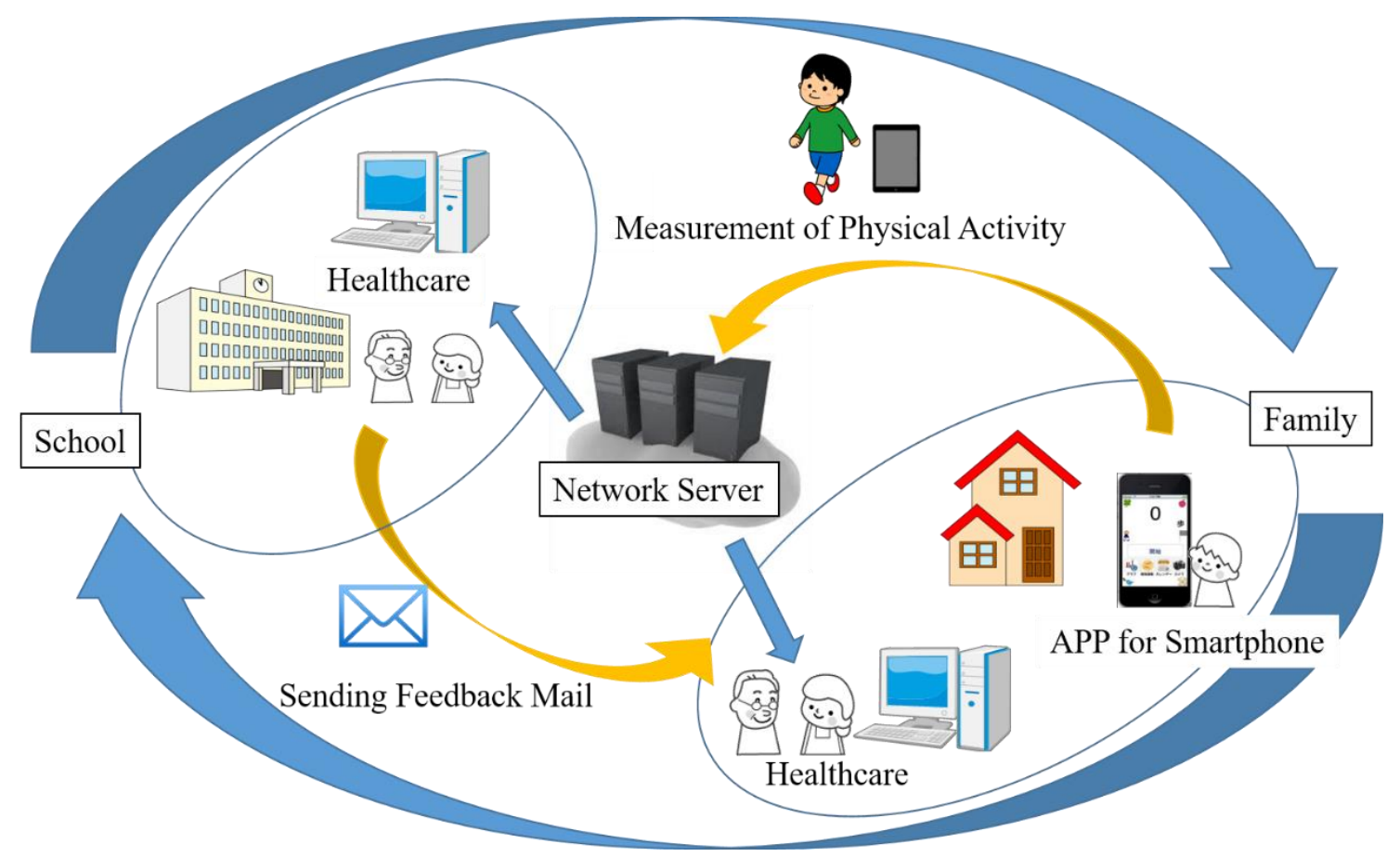

Fig. 1. Diagram of the Distance Education System for Children's Health Promotion.

difficulties, which are traceable to disability conditions and lower overall amounts of daily physical activity ${ }^{(5,6)}$.

From the information presented above, we surmised that kaleidoscopic changes in lifestyle affect the low fitness levels of children with intellectual disabilities and children without disabilities. Furthermore, other social factors might contribute to their lower fitness levels. For instance, children with intellectual disabilities must be accompanied by family members to receive support when attending various community exercise or physical activity programs during their leisure time. Therefore, family circumstances can affect whether or not the children attend these programs. Moreover, families discourage children from playing outside during their leisure time for safety reasons ${ }^{(7)}$.

Researchers have examined the barriers and facilitators of physical activity and exercise among the parents of children with intellectual disabilities. In that study, the specific barriers were categorized as: "Too busy," "To have to care for one's family," "Nobody to do it with," etc. ${ }^{(8)}$. It is surmised that the parents of children with intellectual disabilities have difficulty assuring opportunities for exercise. Therefore, providing opportunities for exercise that these children and their families can do together might motivate them to be more physically active. Accordingly, these opportunities can be expected to promote physical activity and exercise in children with intellectual abilities.

\section{Purpose}

Leading-edge technological developments have improved and advanced human society worldwide. However, opportunities and benefits from these technologies rarely extend to people with physical and mental disabilities. One reason is that people with disabilities represent a small minority of the population. For this reason, demand for such technologies is low. Nevertheless, we think that technology should be used to assist all minorities, especially those with disabilities, helping them to live better and fuller lives.

The purpose of this study was to develop a smartphone application for distance support and education to promote the health of children with intellectual disabilities. Subsequently, we conducted a clinical trial with a child to confirm the effectiveness of the system for fostering a child's exercise habits.

\section{System Development}

Our prior research showed that the time per day during summer vacation devoted to physical activities was significantly shorter than the time during school days devoted to such activities for children with intellectual disabilities.

We think that the families and teachers of children with 
intellectual disabilities must also support the children's healthcare cooperatively during long vacations. In particular, teachers may be able to contact children and family members better and boost their motivation for health promotion during long vacations. However, mutual communication for support during vacations cannot be achieved easily. Accordingly, we developed a distance education system to support children with intellectual disabilities, specifically to foster exercise habits. Figure 1 shows a diagram of the system.

We first selected a smartphone as the system device and started to develop a smartphone application. Next, we built a network server for a smartphone application to save the obtained data and to share the data with teachers and family members. Figure 2 shows an outline of the system.

\subsection{Application for Measuring Physical Activity}

The application for measuring physical activity was developed using the Android 4.0 smartphone operating system. The Android JAVA IDE, Eclipse (Luna Release 4.4.0) programming language was used for software development. The developed application, "Location Collector," has the following application functions.

1] User authentication before working

2] Walking distance measurement using a global positioning system (GPS)

3] Step counting using an accelerometer

4] Camera function for taking photos

5] Automatic upload of all data

Walking distance is measured using the smartphone's built-in GPS. The application, shown in Figure 3, acquires location information using the GPS. It then calculates the walking speed and distance travelled. An original algorithm is used to count the steps with an accelerometer. Scrolling displays the physical activity data in the foreground, but the application can function in the background. The icon for the application includes a status bar to conserve smartphone battery power. Moreover, photographs of the meals that children eat can be taken using the application and uploaded with location information. All collected data are uploaded automatically from the smartphone to a network server. Successive attempts to connect and upload data to the network server are made every $30 \mathrm{~s}$.

\subsection{Cloud Server for Estimation Data}

Next, we built a network server that teachers and families can use to estimate and share a child's physical activities and nutrition data on a web browser. Before using the server software, a teacher must register users. The following information is required for registration.

1] Student ID number, name and address (The address is necessary to show a base point on a server software map.)

2] Account and password for application certification

3] Target distance travelled per day

4] Target time zone for collecting data

5] Upper and lower limits of walking speed (These limits avoid conversion of data collected during movement in vehicles.)
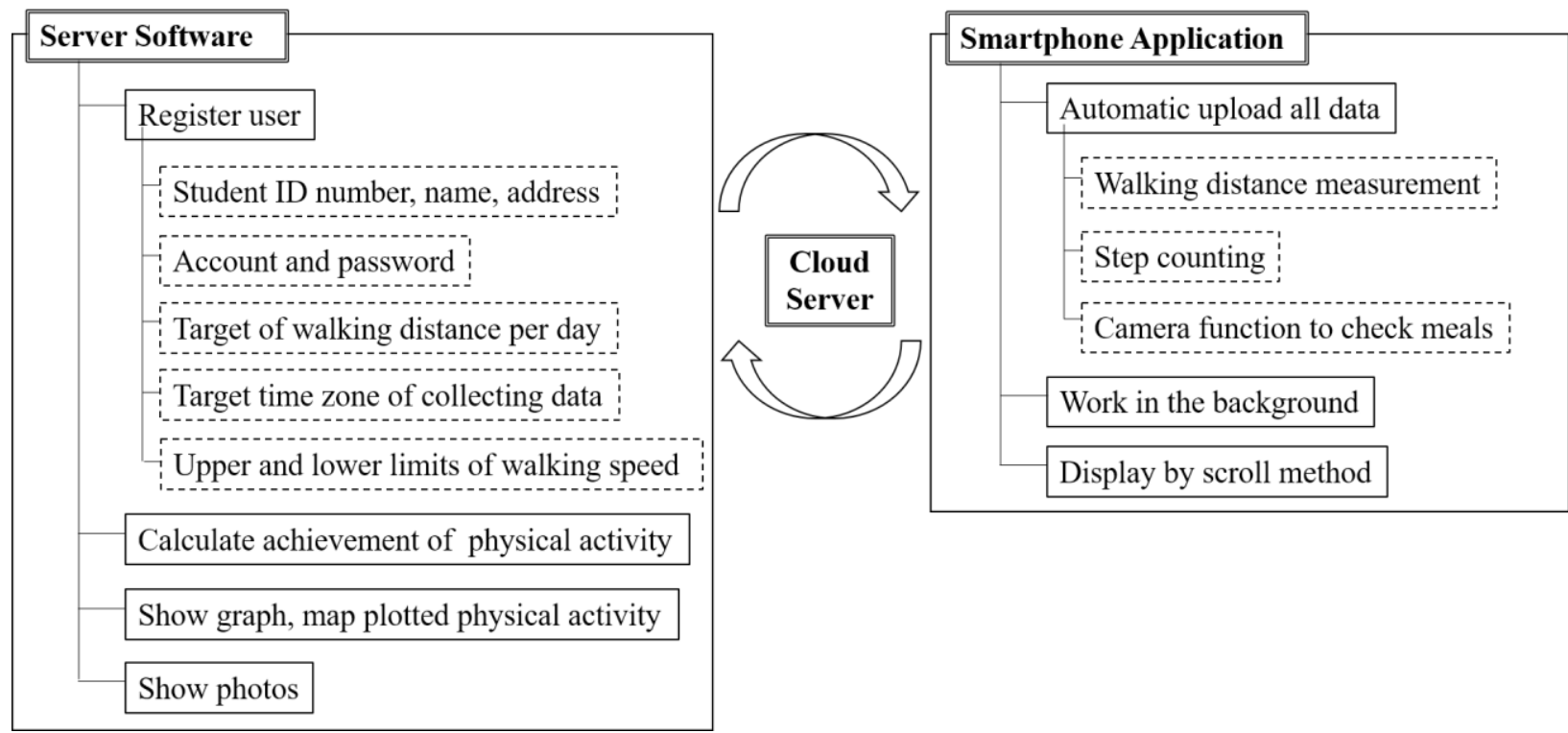

Fig. 2. Outline of the System, Server Software and Smartphone Application. 


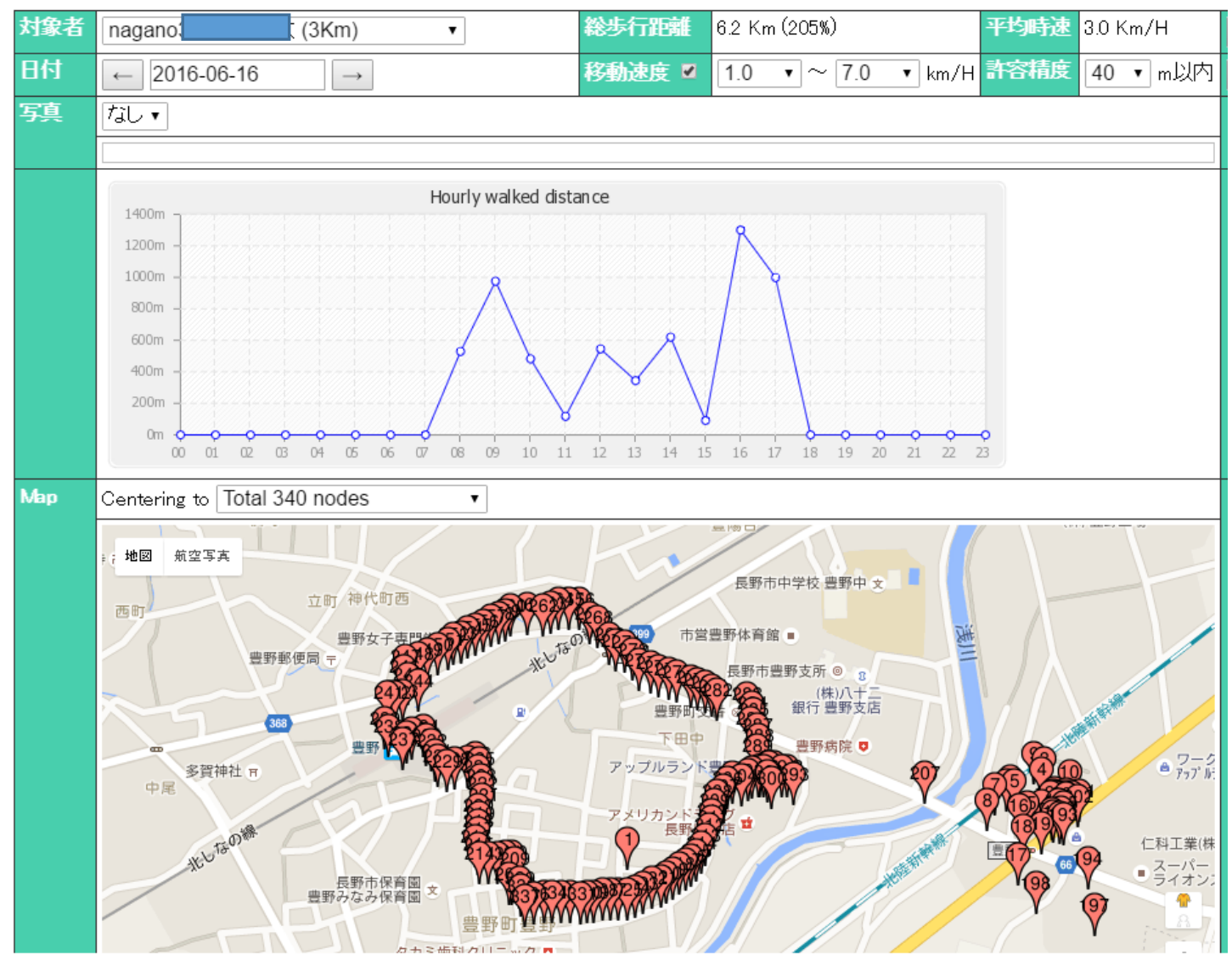

Fig. 3. Server Software Shows Graph, Map and Location Information on PC.

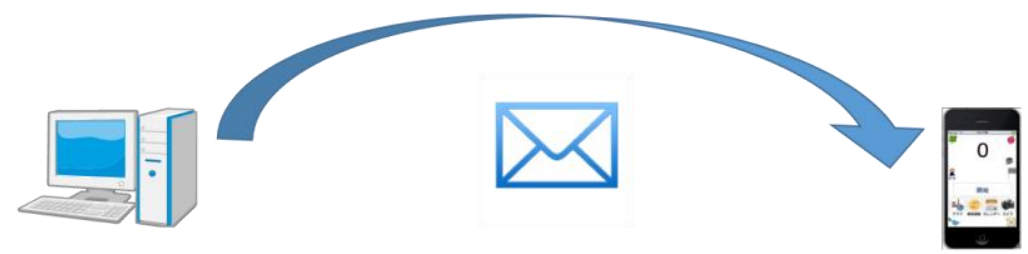

\section{$\theta e \theta e \theta+i$}

2月10日は7.2km歩きました。 歩数は10364歩です。

木曜日に続き、金曜日も歩数が1万歩を超えていました。

きっと、おうちに帰ってから散歩をされているのと同様に、学校でもたくさん体 を動かして活動しているようです。

とても素晴らしいです。

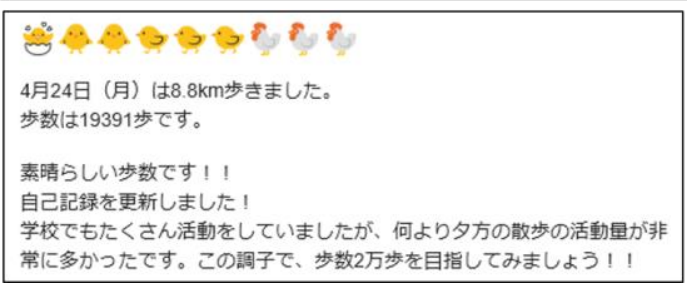

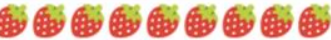

5月19日は8.5 km渉きました。

歩数は17223歩です。

学校でたくさん体を動かし、お母さんとも公園でたくさん体を動かして、 楽しいー日を過ごした樣子がわかります。

これから梅雨の時期が来ると大好きな公園で遊べない日が増えそうなのが 心配ですね。

梅雨が来るまでは、たくさん公園で遊んでください。

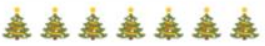

12月25日は6.6km歩きました。 步数は4305歩です。

日曜日はたくさんウォーキングされた㴍子がわかりました。

富山では少し雨が降ってましたが、天候は大丈夫だったのでしょうか？

本格的に冬休みが始まり、もうじき正月ですね。

Fig. 4. Feedback Message with "Emojis" and "Letters".

The web software presents the child's state of physical activity, total distance travelled, average walking speed, steps and time series walking distance graph, and photographs each day. Furthermore, the child's walking path is shown on a Google map (Google Inc.) on the same web page. Data can be exported as a spreadsheet file (Excel; Microsoft Corp.) from the server to a personal computer (PC) [Fig. 2, 3]. After teachers check the data, they send 
messages of encouragement from the PC to the child's smartphone. These messages are the key point for maintaining the motivation of the children and their families for getting plenty of physical activity.

\section{Clinical Trial}

\subsection{Subject and Methods}

We have been conducting a clinical trial with a 10 -yearold boy with Down syndrome since April 2015, in collaboration with National Hospital Organization East Nagano Hospital. The boy is a student at a school in Nagano, Japan for children with special needs. He tends to be overweight.

Before the clinical trial, both the boy and his family received a thorough explanation of the research purpose, research methodology and participation period, possible physical or mental impact, and the risks involved. The parents provided informed consent for the boy to participate in the study.

The boy was instructed to wear a small waist pouch containing a smartphone during the daytime. Because the boy was unable to put the pouch on by himself, his family or teacher would help to fasten it securely. To establish remote communications between the family and members of the research staff, we used Gmail (Google Inc.) to send daily messages to his smartphone. We used Gmail's existing "emojis" when reporting the level of physical activity that he achieved each day [Fig. 4].

The clinical trial has continued for more than 1 year. Accordingly, we compared the data from two periods (for 40 days, from April 9 to May 18, in 2016 and 2017).

\subsection{Results}

Table 1 shows the following data: 1] the total distance travelled/period, 2] the number of steps/day, 3] the frequency of system use/period, and 4] the number of days that the boy and his family exercised together/period [Table 1].
The differences in the state of physical activity and the frequency of system use during the two periods were compared using a $t$-test (SPSS 16.0 Family; SPSS Inc.). Statistical significance was set at the $5 \%$ level. No significant differences were found between data from 2016 and 2017. However, the number of steps/day in 2017 increased by $9.5 \%$ compared to $2016(11772 \pm 6203$ vs $10754 \pm 5941)$. The number of days that the boy and his family exercised together increased by $15.0 \%$ (22/40 days vs $16 / 40$ days). Moreover, he used the system 28 out of 40 days in 2016 (70.0\%), but 36 out of 40 days in 2017 (90.0\%). When he attended day care facilities on Saturdays in 2017, he was not permitted to wear the waist pouch containing the smartphone. For this reason, we were unable to obtain data on Saturdays.

\section{Discussion}

We developed a distance education system to foster exercise habits in children with intellectual disabilities and their family. Many healthcare tools using various devices have been developed for use in modern society, but few tools are available for people with disabilities. These tools are scarce, and those that are available are extremely expensive. Therefore, we have developed a smartphone application and a data server to support the health of children with disabilities.

A noteworthy point of the system is that it can be operated simply. Children who lack knowledge and comprehension of letters and mathematical concepts can easily operate the system via the display.

For this study, we conducted a clinical trial to verify the feasibility of our application to assist a boy with Down syndrome. Before the boy and his family used the application, we explained the effects of exercise for maintaining and promoting the boy's health, and we motivated the boy and his family to exercise habitually. During the clinical trial, we sent daily feedback to encourage them.

The boy's amount of physical activity did not increase significantly between 2016 and 2017. However, his

Table 1. Total Walking Distance, Steps, Utilization of System, Number of exercise days for two periods

\begin{tabular}{|c|c|c|c|c|}
\hline Period [40 days] & $\begin{array}{c}\text { Total } \\
\text { distance travelled } \\
{[\mathrm{km} / \text { period] }}\end{array}$ & $\begin{array}{c}\text { Number of steps } \\
{[\text { step/day] }}\end{array}$ & $\begin{array}{c}\text { Frequency of } \\
\text { system use } \\
\text { [day/period (\%)] }\end{array}$ & $\begin{array}{c}\text { Number of } \\
\text { exercise days } \\
{[\text { day/period (\%)] }}\end{array}$ \\
\hline $\begin{array}{c}2016 \\
\text { [April- May] }\end{array}$ & 173.2 & $10754 \pm 5941$ & $28 / 40(70.0 \%)$ & $16 / 40(40.0 \%)$ \\
\hline $\begin{array}{c}2017 \\
\text { [April- May] }\end{array}$ & 194.8 & $11772 \pm 6203$ & $36 / 40(90.0 \%)$ & $22 / 40(55.0 \%)$ \\
\hline
\end{tabular}


frequency of system use and the number of days that he exercised with his family increased gradually. This is likely because of the support he received from both his family and the researchers. Actually, we could confirm on a PC that the boy and his family exercised after school more frequently in 2017. We surmised that his family changed their mind with regards to maintaining and promoting not only his but also their own health.

Results of the clinical trial indicate that technology is indispensable for implementing distance education to foster exercise habits. However, we also feel strongly that communication between the user and supporter is an essential part of the education. The system was developed using a smartphone, but direct communication between people is essential. We assume that technology combined with personal interaction can promote the welfare of people with disabilities.

\section{Conclusion}

A clinical trial involving a boy with Down syndrome and his family was conducted to test a distance education system for fostering exercise habits. Continuous communication using the system should make fostering exercise habits easier.

As the next stage of this research, we are developing another smartphone application that children with intellectual disabilities and their family can use to check their own data collected by the application and exercise independently.

\section{Acknowledgment}

We thank the staff members of CertPro Co., Ltd., with whom we collaborated to develop the system. Furthermore, we appreciate the doctors, nurses, and physiotherapists at the National Hospital Organization East Nagano Hospital. They gave us valuable advice about the system, and also supported the boy with Down syndrome, his family, and us during the clinical trial.

We received a Grant-in-Aid for Scientific Research, KAKENHI, to conduct our research (Grant No.: 15K17430).

\section{References}

(1) Kensaku Sasayama and Minoru Adachi: "Association Between Daily Physical Activity and Fitness in Junior High School Students", Japan Journal of Physical
Fitness and Sports Medicine, 60, 3, 287-294, 2011

(2) Yuki Hikihara, Kensaku Sasayama, Kyota Okishima, Hidetsugu Mizuuchi, Yutaka Yoshitake, Minoru Adachi and Kaoru Takamatsu: "The Difference of Relationships Between Physical Activity Variables and Physical Fitness in Children and Adolescents: with Special Reference to Amount and Intensity of Physical Activity", Journal of Physical Fitness and Sports Medicine, Vol. 56, pp. 327-338, 2007

(3) Koji Takenaka: "Overview of Issues Pertraining Physical Activity Guideline for Children", Journal of Child Health, 69, 5, 603-609, 2010

(4) Koji Takenaka, " Active Child 60min. : A child's Physical Activity Guideline", Japan Sports Association, 2010

(5) Chisato Ohashi and Ryuichi Kaneko, "A study on the Effects of Daily Physical Activity on the Endurance Ability and the Obesity Index in a Boy with Down's Syndrome", Toyama National College of Maritime Technology, 42, 145-150, 2009

(6) Chisato Ohashi, Shunsuke Akiguchi and Ryohei Isobe, "The Development of an iPhone Application to Support Daily Physical Activity for Mentally Challenged Children, Society for Information Technology \& Teacher Education International Conference 2013, 4343-4345, 2013

(7) Kumiko Ishiguro, Osamu Nakamura and Isami Kinoshita, "A Fundamental Study on the Environmental Arrangement for Leisure Life on the Intellectual Disabled Person. - To Grasp the Actual Condition of Living Activity of the Intellectual Disabled Person and Analysis of the primary Factors-“, Tech. Bull. Hort. Chiba University, 53, 39-45, 1999

(8) Hirokazu Arai and Tomohiro Nakamura,“ Barriers and Facilitators of Physical Activity and Exercise Among the Parents of Children with Intellectual Disability", Japan Journal of Physical Education, Health and Sports Sciences, 54, 213-219, 2009 